\title{
The response of various muscle types to a restriction- re-alimentation feeding strategy in growing pigs
}

\author{
B. Lebret ${ }^{\dagger}$, A. Heyer, F. Gondret and I. Louveau \\ INRA, UMR 1079, Systèmes d'Elevage et Nutrition Animale et Humaine (SENAH - Livestock Production Systems, Animal and Human Nutrition), \\ 35590 Saint-Gilles, France
}

(Received 27 November 2006; Accepted 19 March 2007)

\begin{abstract}
Muscle lipid concentration is known to influence pork eating quality. This study aimed at evaluating the effect of a restriction-re-alimentation feeding strategy on intramuscular fat deposition in pigs. A total of 70 Duroc $\times$ (Large White $\times$ Landrace) pigs (castrated males and females) were used. Ten pigs were first slaughtered at $30 \mathrm{~kg}$ live weight (LW) to determine initial body and muscle composition. From 30 to $80 \mathrm{~kg}$ LW (growing period), pigs were either fed ad libitum (AL) or restricted to $70 \%$ of the ad libitum intake of $A L$ pigs (RA). From 80 to $110 \mathrm{~kg} L W$ (finishing period), both AL and RA pigs were fed ad libitum. In each group, pigs were slaughtered at $80 \mathrm{~kg}(\mathrm{n}=10)$ and at $110 \mathrm{~kg}(\mathrm{n}=20) \mathrm{LW}$. During the growing period, the growth rate of $R A$ pigs was reduced by $30 \%(\mathrm{P}<0.001)$ compared with AL pigs. During the finishing period, RA pigs had a $7 \%(\mathrm{P}=0.09)$ higher growth rate than AL pigs due to compensatory feed intake $(+14 \%)$. Plasma insulin-like growth factor-1 concentration was lower in RA pigs at $80 \mathrm{~kg} L W$, but markedly increased after re-alimentation up to the level observed in $A L$ pigs $(\mathrm{P}<0.001)$. At $80 \mathrm{~kg}$, the leaner carcasses of $R A$ pigs resulted from a more pronounced reduction in fat than in lean tissue deposition rates. Re-alimentation of RA pigs increased fat tissue deposition ( $+160 \%$ for females, $\mathrm{P}<0.01)$ but not lean deposition in the carcass, leading to limited differences in carcass composition between RA and AL pigs at $110 \mathrm{~kg} L W$. Regarding tissue deposition rates, the response to feeding strategy differs between muscles. In the m. biceps femoris (BF), restriction affected lipid $(-50 \%, \mathrm{P}<0.001)$ and protein $(-25 \%, \mathrm{P}<0.001)$ deposition, whereas re-alimentation increased lipid $(+62 \%, \mathrm{P}<0.05)$ but not protein deposition rates. At market weight, the extent of the difference in BF lipid concentration between RA and AL pigs was strongly reduced, but still significant. By contrast, in the $\mathrm{m}$. longissimus, restriction decreased protein but not lipid deposition, whereas neither of them was modified during re-alimentation. Therefore, an increased muscle lipid concentration at $110 \mathrm{~kg}$ LW could not be reached in RA pigs. Modifications of onset and/or duration of restriction and re-alimentation periods should be tested to optimise effects on muscle lipid deposition and thereby achieve improved pork quality.
\end{abstract}

Keywords: carcass, feed intake, growth rate, lipids, pigs

\section{Introduction}

Among the various factors influencing pork eating quality, the positive role of muscle lipid concentration is widely accepted in the literature (Bejerholm and Barton-Gade, 1986; Fernandez et al., 1999). Age-related increase in intramuscular (i.m.) lipid content during normal postnatal growth in pigs might be modulated by animal energy intake (Ellis et al., 1996; Blanchard et al., 1999). For instance, feed (energy) restriction during the growing-finishing period is associated with lower muscle lipid concentration compared with ad libitum feeding (Wood et al., 1996; Lebret et al.,

${ }^{\dagger}$ E-mail: Benedicte.Lebret@rennes.inra.fr
2001), whereas feed restriction associated with increased energy/protein intake ratio leads to higher muscle lipid concentration (Lebret et al., 2001).

In pigs, feed restriction during initial growth followed by re-alimentation during finishing results in increased growth rate (compensatory growth) compared with ad libitum feeding (Campbell et al., 1983; Donker et al., 1986). The compensation in the rate - and often efficiency - of body gain results mainly from an increase in adipose tissue and internal organ growth, but not from a higher carcass lean deposition (Bikker et al., 1996a and b; Skiba et al., 2004). However, the impact of this feeding strategy on muscle lipid concentration at market weight has been scarcely described in pigs. Moreover, it has been shown that pigs exhibiting compensatory growth might have increased muscle protein 
turn-over and thereby improved pork tenderness, compared with control pigs (Therkildsen et al., 2002; Kristensen et al., 2004). Thus, a long-term restriction followed by re-alimentation up to market slaughter weight may be a strategy to increase the age at slaughter and thereby the potential for i.m. lipid deposition, and/or modify the composition of muscle weight gain that might consequently improve pork eating quality.

The purpose of the present study was to evaluate the response of pigs to a $30 \%$ feed restriction from 30 to up to $80 \mathrm{~kg}$ live weight (LW) and subsequent re-alimentation up to $110 \mathrm{~kg} \mathrm{LW}$ on growth and composition of weight gain at both carcass and muscle levels, with special focus on loin and ham muscles. Since insulin-like growth factor-1 (IGF-1) is known to regulate muscle growth, changes in plasma IGF-1 concentration in response to feeding strategy were also examined.

\section{Material and methods}

\section{Animals}

A total of 70 Duroc $\times$ (Large White $\times$ Landrace) pigs (females and castrated males) from 10 litters originated from two sires were used in the experiment. At the average LW of $28 \mathrm{~kg}$ and average age of 69 days (end of the postweaning period), 30 pairs of littermates (by sex) were chosen on the basis of their weight at birth and at weaning, and growth rate up to $28 \mathrm{~kg} \mathrm{LW}$. Within litter and sex, pairs of littermates (blocked by LW) were randomly assigned to one of the following feeding regimen: $A L=$ pigs were fed ad libitum a standard growing diet (Table 1) during both growing (30-80 kg LW) and finishing (80-110 kg LW) periods, i.e. control group; $n=15$ castrated males and 15 females; or RA $=$ from 30 to $80 \mathrm{~kg} \mathrm{LW}$, pigs were fed the standard diet at $70 \%$ of the average ad libitum intake of the control (AL) pigs of the same sex, on a LW basis, and from 80 to $110 \mathrm{~kg} \mathrm{LW}$, they were fed ad libitum; $n=15$ castrated males and 15 females. This restriction level was chosen in order to reduce severely the growth rate during the growing period, i.e. by around $30 \%$ as estimated previously (Quiniou et al., 1995; Lebret et al., 2001) and thereby increase the occurrence of further compensatory feed intake and possibly the compensatory growth during re-alimentation (Campbell et al., 1983). A growing diet was used all along the experiment to satisfy the protein requirement of RA pigs during re-alimentation that could be increased compared with control pigs.

In addition to AL and RA pigs, 10 piglets (five castrated males and five females) from five of the 10 litters used in the experiment and representative of their experimental littermates according to their weight at birth and growth rate up to $30 \mathrm{~kg} \mathrm{LW}$, were slaughtered at the average LW of 28.7 (s.d. 2.6) kg (average age of 69.7 (s.d. 2.3) days). They were used as controls at the start of the experiment to enable further calculations of composition of weight gain (LW30).
Table 1 Composition (ingredients and chemical composition) and nutritional value of the diet

\begin{tabular}{lr}
\hline \hline Ingredients (\%) & \\
Wheat & 24.37 \\
Maize & 15.00 \\
Barley & 24.56 \\
Soya-bean meal & 23.00 \\
Rapeseed oil & 2.00 \\
Wheat bran & 5.00 \\
Molasses & 3.00 \\
Lysine 50 & 0.12 \\
D-L-methionine & 0.03 \\
L-threonine & 0.03 \\
Dicalcium phosphate & 0.56 \\
Calcium carbonate & 1.18 \\
Marine salt & 0.45 \\
Trace minerals and vitamin mixture & 0.50 \\
Phytase & 0.20 \\
Chemical composition (\% of the distributed diet) & \\
Dry matter & 87.20 \\
Crude protein & 17.72 \\
Crude fat & 4.24 \\
Crude fibre & 3.69 \\
Starch & 38.09 \\
Ash & 5.13 \\
Nutritional value & \\
Net energy (MJ/kg) & \\
Digestible lysine (\%) & 9.75 \\
\hline \hline
\end{tabular}

${ }^{\dagger}$ Estimated from tables of INRA - AFZ (2002).

The $\mathrm{AL}$ and $\mathrm{RA}$ pigs were reared in individual pens ( $2.25 \mathrm{~m}^{2}$ per pig, concrete floor without straw) in the same room. They were weighed weekly, after overnight fasting, until slaughter. During the 1st week, the RA pigs received $70 \%$ of the average daily feed consumption of pigs from this genotype and reared in similar conditions calculated in a previous experiment, i.e. the RA pigs received $1.0 \mathrm{~kg} /$ day. This finally corresponded to $67 \%$ of the actual feed intake of the AL pigs during the first experimental week. Thereafter, the feeding schemes of the RA pigs were calculated weekly, within sexes, on the basis of LW and average feed intake of the AL group.

Pigs were slaughtered in the experimental abattoir of INRA-SENAH. LW30 pigs $(n=10)$ were slaughtered at the start of the experiment. At $80 \mathrm{~kg}$ LW (LW80), $n=20$ pigs, i.e. five castrated males and five females per feeding regimen and representative of the $A L$ and RA pigs in terms of litter, weight at start of the growing period and daily gain were slaughtered. The remaining pigs $(n=40)$ were slaughtered at $110 \mathrm{~kg}$ LW (LW110). After overnight fasting, the pigs were transported individually over a short distance and kept separately for at least $2 \mathrm{~h}$ at the abattoir before electrical stunning and ex-sanguination.

\section{Hormone concentrations}

Blood samples were collected from the RA pigs 8 days after re-feeding $(90 \mathrm{~kg} \mathrm{LW})$ and at ex-sanguination of LW30, 
LW80 and LW110 pigs after overnight fasting. Blood was collected in heparin; plasma was prepared by low-speed centrifugation $\left(2500 \times \mathbf{g}\right.$ for $10 \mathrm{~min}$ at $\left.4^{\circ} \mathrm{C}\right)$ and stored at $-20^{\circ} \mathrm{C}$. Basal plasma concentrations of insulin were measured by radio-immunoassay (RIA) according to Prunier et al. (1993). Concentrations of IGF-1 in plasma were determined using a double RIA antibody after acid-ethanol extraction (Louveau and Bonneau, 1996). All the samples were analysed in duplicate within single assay. The coefficient of variation (CV) was $6.3 \%$ for insulin and $7.3 \%$ for IGF-1.

\section{Carcass and muscle traits}

Weights of hot carcass, perirenal fat, liver and entire gut, depleted by stripping and flushing, were measured on the day of slaughter. The same day, backfat thickness at carcass mid line was measured at the last rib level with a ruler. Backfat and muscle depths were also determined on LW80 and LW110 pigs using a Fat-0-Meater probe (SFK, Herlev, Denmark): fat depth was determined at the $3 \mathrm{rd} / 4$ th lumbar vertebra level, $8.0 \mathrm{~cm}$ from the mid line (G1), and fat (G2) and muscle (M2) depths were determined at the $3 \mathrm{rd} / 4$ th last rib level, $6.0 \mathrm{~cm}$ from the mid line.

After $24 \mathrm{~h}$ at $4^{\circ} \mathrm{C}$, weights of the carcass and of wholesale cuts of the left side (ham, loin, shoulder, belly and backfat) were recorded. The entire longissimus muscle (LM) was dissected from the right loin piece and weighed. The left ham was dissected into muscle (including isolated biceps femoris (BF), semimembranosus (SM), semitendinosus (ST)), external fat, internal fat and bones. The different parts were then weighed.

Carcass lean meat content was calculated from the weight of wholesale cuts using the equation $\left[\mathrm{LMC}_{\text {calc }}=\right.$ $5.684+1.197 \%$ ham $+1.076 \%$ loin $-1.059 \%$ backfat] (Métayer and Daumas, 1998). Moreover, for pigs slaughtered at $110 \mathrm{~kg}$ LW only, carcass lean meat content was estimated from linear measurements G1, G2 and M2 (lean meat content ${ }_{\mathrm{FoM}}=\mathrm{LMC}_{\mathrm{FoM}}$ ) according to Daumas et al. (1998).

\section{Muscle composition}

The day after slaughter, transverse sections of LM (last rib level) and BF muscles were taken from all pigs (right half carcass), trimmed of external fat and epimysium, minced, freeze-dried, pulverised and kept at $-20^{\circ} \mathrm{C}$ under vacuum before chemical analyses. Intramuscular lipid concentration was determined after chloroform/methanol $(2: 1 \mathrm{v} / \mathrm{v})$ extraction according to Folch et al. (1957). Protein concentration was determined from nitrogen concentration (Dumas method, Association of Official Analytical Chemists, 1990) using a multiplication factor of 6.25. Collagen concentration was calculated from hydroxyproline determination (Bergman and Loxley, 1963) using a multiplication factor of 7.14 (Etherington and Sims, 1981). Heat solubility of collagen was determined according to Hill (1966). Briefly, approximately $300 \mathrm{mg}$ of muscle powder was homogenised in $7 \mathrm{ml}$ of $1 / 4$-ionic strength Ringer's solution $(36.4 \mathrm{mmol} / \mathrm{l}$ $\mathrm{NaCl}, 0.8 \mathrm{mmol} / / \mathrm{KCl}, 0.68 \mathrm{mmol} / \mathrm{l} \mathrm{CaCl}_{2}$ and $0.6 \mathrm{mmol} / \mathrm{l}$ $\mathrm{NaHCO}_{3}$ ) for $1 \mathrm{~h}$ at $20^{\circ} \mathrm{C}$ (rotary stirring machine), heated at $77^{\circ} \mathrm{C}$ for $1 \mathrm{~h}$ (stirring water bath) and centrifuged at $4000 \times \mathbf{g}$ for $30 \mathrm{~min}$ at $20^{\circ} \mathrm{C}$. The supernatant was collected, and the pellet was rinsed by $3 \mathrm{ml}$ of the Ringer's solution, homogenised and centrifuged at $4000 \times \mathbf{g}$ for $30 \mathrm{~min}$ at $20^{\circ} \mathrm{C}$. Supernatants were pooled and used for hydroxyproline determination (Bergman and Loxley, 1963). Thermal solubility of collagen was expressed as percentage of the collagen concentration.

\section{Statistical analyses}

Data were submitted to an ANovA using the mixed procedure of Statistical Analysis Systems Institute (2000) by slaughter weights (LW80 and LW110). The model included the fixed effects of feeding regimen (F) (AL/RA), sex (S) (castrated male/female), and their interaction $(F \times S)$, and the random effect of litter. Final LW was included as covariate in the model for the calculations of hot carcass and organ weights.

\section{Results}

\section{Growth performance}

The Feeding levels had significant effects on growth performance of the pigs (Table 2). As expected, the average daily feed intake (ADFI) of the RA pigs was reduced by $30 \%$ during the growing period, whereas feed efficiency was not modified. This led to a $31 \%$ reduction in average daily weight gain in RA pigs compared with AL pigs. Thus, the growing period was extended by 25 days in the RA pigs. ADFI of the RA pigs in the finishing period was $14 \%$ higher compared with AL pigs, thus demonstrating a compensatory feed intake for the RA pigs with re-alimentation. Feed efficiency was lower $(P<0.05)$ in RA pigs compared with AL pigs during re-alimentation. This gave rise to a $7 \%$ increase in average daily gain (compensatory growth) in RA compared with AL pigs, although not significant $(P=0.094)$. Duration of the finishing period was around 3 days shorter in the RA pigs. Consequently, RA pigs were 23 days older at slaughter at $110 \mathrm{~kg}$ LW than AL pigs.

Females had a lower ADFI than castrated males during both growing $(1.86$ and $1.97 \mathrm{~kg} / \mathrm{day}$, respectively, $P<0.001)$ and finishing $(3.30$ and $3.79 \mathrm{~kg} /$ day, respectively, $P<0.01)$ periods. They had also a higher feed efficiency than castrated males during growing $(0.40$ and $0.39 \mathrm{~kg} / \mathrm{kg}$ $P<0.05)$ and lower daily gain during finishing (1016 and $1129 \mathrm{~g} /$ day, $P<0.05)$. There was no significant interaction between feeding regimen and sex for growth performance data.

\section{Hormones}

Plasma IGF-1 concentration increased from LW30 to LW80 in AL pigs, but did not change in RA pigs over this period. 
Lebret, Heyer, Gondret and Louveau

Table 2 Growth performance (least-square means) of pigs between 30 to $80 \mathrm{~kg}$ live weight (LW) and 80 to $110 \mathrm{~kg}$ LW and allocated to either ad libitum (AL) or restriction-re-alimentation (RA) feeding strategy

\begin{tabular}{|c|c|c|c|c|c|c|c|c|c|c|c|c|}
\hline & \multicolumn{3}{|c|}{$30-80 \mathrm{~kg} \mathrm{LW}$} & \multicolumn{3}{|c|}{ Significance $^{+}$} & \multicolumn{3}{|c|}{$80-110 \mathrm{~kg} \mathrm{LW}$} & \multicolumn{3}{|c|}{ Significance $^{\dagger}$} \\
\hline & $A L$ & RA & s.e. & $\mathrm{F}$ & $S$ & $\mathrm{~F} \times \mathrm{S}$ & $A L$ & RA & s.e. & $\mathrm{F}$ & $S$ & $\mathrm{~F} \times \mathrm{S}$ \\
\hline No. of animals & 30 & 30 & & & & & 20 & 20 & & & & \\
\hline Initial live weight $(\mathrm{kg})$ & 28.2 & 28.2 & 0.56 & & & & 28.6 & 28.4 & 0.67 & & & \\
\hline Initial age (days) & 68.8 & 68.8 & 0.28 & & & & 68.8 & 68.8 & 0.28 & & & \\
\hline Final live weight $(\mathrm{kg})$ & 80.6 & 80.5 & 0.58 & & & & 111.5 & 110.3 & 0.49 & & & \\
\hline Final age (days) & 127.3 & 152.5 & 0.66 & $* * *$ & & & 157.8 & 180.5 & 1.65 & $* * *$ & & \\
\hline Period duration (days) & 58.6 & 84.0 & 0.66 & *** & & & 30.4 & 27.6 & 1.28 & * & * & \\
\hline Average daily feed intake $(\mathrm{kg})$ & 2.26 & 1.57 & 0.02 & $* * *$ & $* * *$ & & 3.31 & 3.78 & 0.10 & ** & ** & \\
\hline Average daily gain (g/day) & 895 & 621 & 6.93 & *** & & & 1035 & 1110 & 38.1 & & * & \\
\hline Feed efficiency $(\mathrm{kg} / \mathrm{kg})$ & 0.40 & 0.40 & 0.01 & & * & & 0.32 & 0.29 & 0.01 & * & & \\
\hline
\end{tabular}

${ }^{\dagger}$ Significance for the effects of feeding regimen $(F)$, sex $(S)$, and their interaction $(F \times S)$.

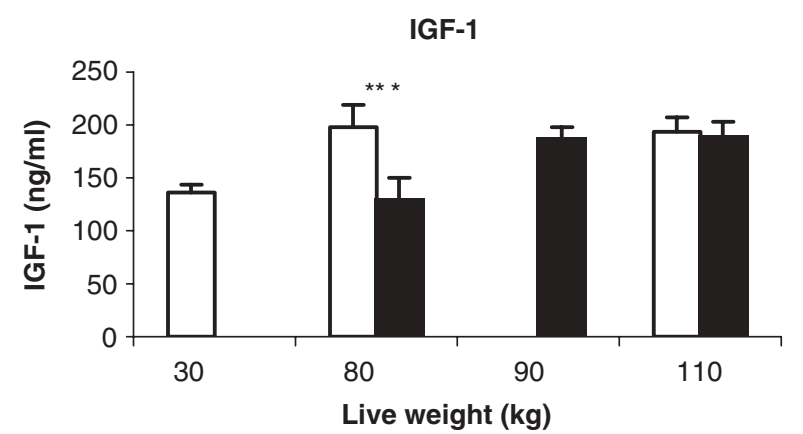

Figure 1 Plasma insulin-like growth factor-1 concentration according to live weight and feeding regimen; $\square=$ ad libitum (AL); $\mathbf{\square}=$ restriction-re-alimentation (RA); ${ }^{* *}$ Indicates statistically significant difference between AL and RA groups, $P<0.001$.

This resulted in a $30 \%$ lower $(P<0.001)$ IGF-1 concentration in RA pigs than AL pigs at LW80 (Figure 1). IGF-1 concentration increased rapidly in RA pigs after 1 week of re-alimentation, up to the level observed in the AL pigs at the end of the finishing period. No difference in plasma insulin concentration was observed between AL pigs and RA pigs at both $80 \mathrm{~kg}(2.73$ and $2.30 \mu \mathrm{IU} / \mathrm{ml}$ for AL and RA pigs, respectively, $P>0.05)$ and $110 \mathrm{~kg} \operatorname{LW}(2.34$ and $2.60 \mu \mathrm{lU} / \mathrm{ml}$ for $\mathrm{AL}$ and RA pigs, respectively, $P>0.05)$.

\section{Carcass composition}

At the end of the growing period, the hot carcass weight and dressing percentage were not significantly different between RA and AL pigs. However, lower $(P<0.05)$ weights of internal organs (depleted gut, liver and perirenal fat) were found in RA pigs (Table 3). In contrast, the carcass composition was influenced by feed restriction. RA pigs had leaner carcasses than AL pigs as shown by their thinner backfat $(P<0.05)$ and higher LM weight $(P<0.05)$. Carcass composition at LW80 shifted towards higher portion of valuable cuts (ham, loin) and lower proportions of belly and backfat, and consequently higher calculated lean meat content $\left(\mathrm{LMC}_{\text {calc }}\right)(+3.6 \%$ points, $P<0.001)$ in the RA pigs than in AL pigs. Dissected ham displayed similar differences in fat and lean tissue proportions between the two feeding groups, with a higher proportion of muscle (in particular SM, data not shown) and a lower proportion of subcutaneous fat in the RA pigs compared with AL pigs.

Whatever the feeding regimen, females had lower proportion of backfat, higher ham percentage and higher muscle proportion in ham than castrated males, leading to higher $\mathrm{LMC}_{\text {calc }}$ in females than in castrates $(60.2$ and $56.8 \%$, respectively, $P<0.001$ ). No significant interaction between feeding regimen and sex were found on carcass composition at LW80. At $110 \mathrm{~kg} \mathrm{LW}$, weights of internal organs and LM did not differ between RA and AL pigs. Differences in backfat thickness were much lower at 110 than at $80 \mathrm{~kg} \mathrm{LW}$, and backfat proportion was no longer different between RA and AL pigs. Carcass and ham composition were not affected by the feeding strategies. Altogether, estimated lean meat content was 1.6 points higher $(P<0.05)$ in the RA pigs due to their lower backfat thickness, whereas $L M C_{\text {calc }}$ did not significantly differ between RA and AL pigs.

LW110 females had higher carcass dressing percentage in connection with lower weight of gut, than castrated males. Ham proportion and LM weight were higher, and backfat proportion was lower in females, leading to a higher $\mathrm{LMC}_{\text {calc }}$ for females than castrated males $(55.4 \%$ and $52.3 \%$, respectively, $P<0.001)$. However, muscle and backfat depth measurements, and consequently estimated $\mathrm{LMC}_{\mathrm{FoM}}$, did not significantly differ between sexes.

Numerous significant interactions between sex and feeding regimen were found on carcass traits evaluated at $110 \mathrm{~kg}$ LW. The RA feeding strategy significantly decreased thickness and proportion of backfat and ham fat in castrated males, but not in females (e.g. $-4.8 \mathrm{~mm}$, 
Feeding strategy and muscle composition in pigs

Table 3 Carcass quality traits (least-square means) of pigs slaughtered at 30, 80 or $110 \mathrm{~kg}$ live weight and allocated to either ad libitum (AL) or restriction-re-alimentation $(R A)$ feeding strategy

\begin{tabular}{|c|c|c|c|c|c|c|c|c|c|c|c|c|c|c|}
\hline & \multicolumn{2}{|c|}{ LW30 } & \multicolumn{3}{|c|}{ LW80 } & \multicolumn{3}{|c|}{ Significance $^{\dagger}$} & \multicolumn{3}{|c|}{ LW110 } & \multicolumn{3}{|c|}{ Significance $^{\dagger}$} \\
\hline & & $\overline{\text { s.e. }}$ & $\mathrm{AL}$ & RA & $\overline{\text { s.e. }}$ & $\mathrm{F}$ & $S$ & $\bar{F} \times \mathrm{S}$ & $\mathrm{AL}$ & RA & s.e. & $\mathrm{F}$ & $S$ & $\mathrm{~F} \times \mathrm{S}$ \\
\hline No. of animals & 10 & & 10 & 10 & & & & & 20 & 20 & & & & \\
\hline \multicolumn{15}{|l|}{ Carcass traits } \\
\hline Hot carcass weight $(\mathrm{kg})^{\ddagger}$ & 21.2 & 0.7 & 62.1 & 63.0 & 0.35 & & & & 87.4 & 87.5 & 0.41 & & & \\
\hline Dressing (\%) & 74.0 & 1.2 & 76.7 & 77.8 & 0.45 & & & & 78.7 & 79.0 & 0.39 & & * & \\
\hline Depleted gut $(\mathrm{kg})^{\ddagger}$ & 0.20 & 0.1 & 4.76 & 4.26 & 0.01 & ** & & & 5.80 & 5.84 & 0.10 & & ** & \\
\hline Liver $(\mathrm{kg})^{\ddagger}$ & 0.73 & 0.1 & 1.65 & 1.41 & 0.04 & ** & & & 1.98 & 1.96 & 0.04 & & * & * \\
\hline Perirenal fat $(\mathrm{kg})^{\ddagger}$ & 0.12 & 0.1 & 0.58 & 0.46 & 0.03 & * & & & 1.27 & 1.18 & 0.08 & & & \\
\hline M. longissimus $(\mathrm{kg})^{\ddagger}$ & 0.56 & 0.1 & 1.85 & 2.00 & 0.04 & * & & & 2.51 & 2.52 & 0.06 & & $* * *$ & * \\
\hline Muscle thickness (mm) & & & 49.6 & 53.2 & 2.56 & & & & 60.7 & 61.8 & 1.88 & & & \\
\hline \multicolumn{15}{|l|}{ Backfat thickness } \\
\hline Last rib level (mm) & 9.8 & 1.3 & 13.9 & 11.5 & 0.72 & * & & & 19.8 & 18.2 & 1.05 & * & & \\
\hline Average $(\mathrm{G} 1-\mathrm{G} 2)(\mathrm{mm})$ & & & 13.4 & 10.1 & 0.70 & ** & & & 17.9 & 16.3 & 0.48 & * & & $* * *$ \\
\hline $\operatorname{LMC}_{\mathrm{FoM}}(\%)^{\S}$ & & & & & & & & & 60.5 & 62.1 & 0.50 & * & & $* * *$ \\
\hline $\mathrm{LMC}_{\text {calc }}(\%)^{\S}$ & 58.8 & 0.5 & 56.7 & 60.3 & 0.84 & $* * *$ & $* * *$ & & 53.6 & 54.1 & 0.64 & & $* * *$ & $*$ \\
\hline \multicolumn{15}{|l|}{ Carcass composition (\%) } \\
\hline Ham & 26.8 & 0.2 & 24.8 & 25.9 & 0.24 & $* * *$ & ** & & 24.3 & 24.5 & 0.19 & & $* * *$ & \\
\hline Loin & 27.0 & 0.4 & 27.2 & 28.1 & 0.33 & * & & & 26.4 & 26.3 & 0.23 & & * & \\
\hline Shoulder & 25.4 & 0.2 & 24.4 & 24.9 & 0.24 & & & & 24.6 & 24.5 & 0.19 & & & \\
\hline Belly & 12.6 & 0.3 & 13.8 & 12.8 & 0.36 & * & & & 13.9 & 14.4 & 0.21 & & & \\
\hline Backfat & 4.6 & 0.2 & 6.1 & 4.6 & 0.31 & $* * *$ & $* * *$ & & 7.7 & 7.2 & 0.25 & & $* * *$ & $* *$ \\
\hline \multicolumn{15}{|l|}{ Ham dissection (\%) } \\
\hline Muscle & 65.8 & 0.9 & 64.8 & 68.0 & 0.77 & $* * *$ & * & & 64.0 & 64.2 & 0.60 & & ** & \\
\hline Total fat & 10.3 & 0.8 & 16.6 & 12.0 & 0.76 & $* * *$ & & & 18.0 & 17.7 & 0.78 & & * & * \\
\hline Subcutaneous fat & 7.7 & 0.6 & 13.0 & 9.0 & 0.73 & $* *$ & & & 14.3 & 14.2 & 0.64 & & * & * \\
\hline Intermuscular fat & 2.6 & 0.3 & 3.6 & 2.9 & 0.24 & & & & 3.8 & 3.5 & 0.31 & & * & \\
\hline
\end{tabular}

${ }^{+}$Significance for the effects of feeding regimen $(F)$, sex $(S)$, and their interaction $(F \times S)$.

${ }^{\ddagger}$ Final live weight was included as a covariable in the model for calculation of this trait.

${ }^{\S} \mathrm{LMC}=$ lean meat content.

$P<0.001$, and $+1.2 \mathrm{~mm}, P>0.10$ for average $\mathrm{G} 1-\mathrm{G} 2$ backfat thickness between the AL and RA pigs in castrated males and in females, respectively, $P<0.001$ ). This led to a higher $\mathrm{LMC}_{\mathrm{FoM}}$ and $\mathrm{LMC}_{\text {calc }}$ for RA than $\mathrm{AL}$ castrated males, but not for RA compared with AL females (Figure 2).

\section{Muscle composition}

Feeding strategy did not influence LM chemical composition of pigs slaughtered at $80 \mathrm{~kg} \mathrm{LW}$ (Table 4). In the BF, lipid concentration was lower (0.57 percentage unit, $P<0.001$ ) in RA pigs compared with AL pigs, whereas protein and collagen concentrations, and collagen solubility were not modified between groups. Sex had no significant effect on muscle composition in LW80 pigs.

At slaughter at $110 \mathrm{~kg} \mathrm{LW}$, LM protein concentration was slightly lower in RA pigs than in AL pigs. In the BF, the magnitude of the difference previously observed between RA and AL pigs for lipid concentration was reduced but still significant (0.22 percentage units, $P<0.05)$. In addition, BF collagen concentration was lower in RA pigs compared with AL pigs. Females had higher protein concentration in LM

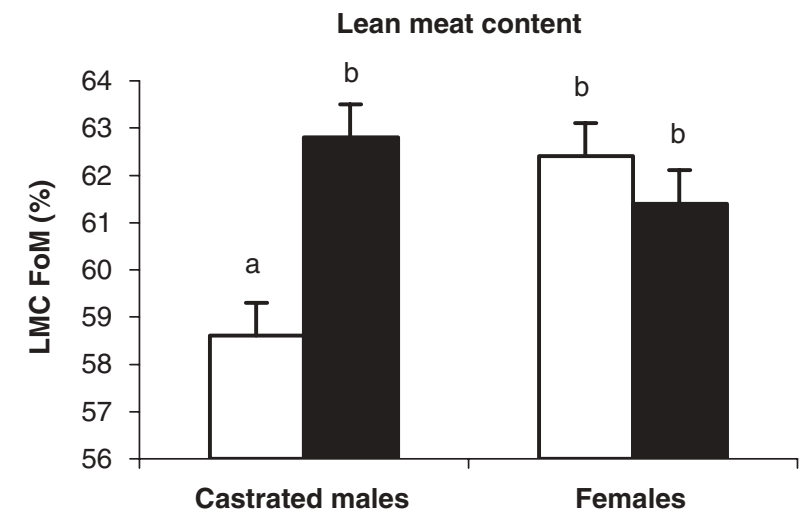

Figure 2 Estimated lean meat content $\left(\mathrm{LMC}_{\mathrm{FoM}}\right)$ of castrated males and female pigs slaughtered at $110 \mathrm{~kg}$ live weight and allocated to different feeding regimen. $\square=$ ad libitum (AL); $\mathbf{\square}=$ restriction-re-alimentation (RA). Different superscripts indicate statistically significant differences $(P<0.05)$

and $\mathrm{BF}$, and lower lipid concentration in $\mathrm{LM}$, than castrated males. No significant interactions were found between feeding strategies and sex for muscle composition. 
Lebret, Heyer, Gondret and Louveau

Table 4 Chemical composition (least-square means) of m. longissimus and m. biceps femoris from pigs slaughtered at 30, 80 or $110 \mathrm{~kg}$ live weight and allocated to either ad libitum (AL) or restriction-re-alimentation (RA) feeding strategy

\begin{tabular}{|c|c|c|c|c|c|c|c|c|c|c|c|c|c|c|}
\hline & \multicolumn{2}{|c|}{ LW30 } & \multicolumn{3}{|c|}{ LW80 } & \multicolumn{3}{|c|}{ Significance $^{+}$} & \multicolumn{3}{|c|}{ LW110 } & \multicolumn{3}{|c|}{ Significance $^{+}$} \\
\hline & & s.e. & $\mathrm{AL}$ & RA & s.e. & $\mathrm{F}$ & $\mathrm{S}$ & $\mathrm{F} \times \mathrm{S}$ & $\mathrm{AL}$ & RA & s.e. & $\mathrm{F}$ & $S$ & $\mathrm{~F} \times \mathrm{S}$ \\
\hline No. of animals & 10 & & 10 & 10 & & & & & 20 & 20 & & & & \\
\hline \multicolumn{15}{|l|}{ M. lonqissimus } \\
\hline Lipid (\%) & 1.23 & 0.02 & 1.66 & 1.62 & 0.15 & & & & 2.07 & 1.98 & 0.10 & & ** & \\
\hline Crude protein (\%) & 20.7 & 0.20 & 22.5 & 22.5 & 0.15 & & & & 23.5 & 23.1 & 0.12 & ** & ** & \\
\hline Collagen (\%) & 0.49 & 0.01 & 0.47 & 0.47 & 0.02 & & & & 0.41 & 0.43 & 0.01 & & & \\
\hline Solubility $(\%)^{\ddagger}$ & 36.6 & 1.40 & 24.9 & 22.9 & 1.76 & & & & 19.0 & 17.0 & 0.76 & & & \\
\hline \multicolumn{15}{|l|}{ M. biceps femoris } \\
\hline Lipid (\%) & 1.29 & 0.05 & 2.11 & 1.54 & 0.10 & $* * *$ & & & 2.17 & 1.95 & 0.12 & * & & \\
\hline Crude protein (\%) & 19.7 & 0.30 & 21.7 & 21.5 & 0.20 & & & & 22.0 & 21.9 & 0.13 & & ** & \\
\hline Collagen (\%) & & & 0.71 & 0.73 & 0.03 & & & & 0.73 & 0.64 & 0.02 & *** & & \\
\hline Solubility $(\%)^{b}$ & & & 23.3 & 23.0 & 1.25 & & & & 20.4 & 19.3 & 0.65 & & & \\
\hline
\end{tabular}

${ }^{\dagger}$ Significance for the effects of feeding regimen $(F)$, sex $(S)$, and their interaction $(F \times S)$.

tThermal solubility of collagen, in percentage of total collagen.

Table 5 Muscle, protein and fat deposition (least-square means) in ham, m. longissimus and $\mathrm{m}$. biceps femoris of pigs between 30-80 $\mathrm{kg}$ live weight, and $80-110 \mathrm{~kg} L W$, and allocated to either ad libitum (AL) or restriction-re-alimentation (RA) feeding strategy

\begin{tabular}{|c|c|c|c|c|c|c|c|c|c|c|c|c|}
\hline & \multicolumn{3}{|c|}{$30-80$ kg LW } & \multicolumn{3}{|c|}{ Significance $^{\dagger}$} & \multicolumn{3}{|c|}{$80-110 \mathrm{~kg} \mathrm{LW}$} & \multicolumn{3}{|c|}{ Significance $^{\dagger}$} \\
\hline & $\mathrm{AL}$ & RA & s.e. & $\mathrm{F}$ & $S$ & $\mathrm{~F} \times \mathrm{S}$ & $\mathrm{AL}$ & RA & s.e. & $\mathrm{F}$ & $S$ & $\mathrm{~F} \times \mathrm{S}$ \\
\hline No. of animals & 10 & 10 & & & & & 20 & 20 & & & & \\
\hline \multicolumn{13}{|l|}{ Deposition rates in ham ${ }^{\ddagger}$} \\
\hline Muscle (g/day) & 49.8 & 40.1 & 1.73 & $* * *$ & & & 59.6 & 47.3 & 4.67 & * & & \\
\hline Total fat (g/day) & 15.5 & 7.5 & 0.60 & $* * *$ & & & 20.8 & 31.5 & 2.72 & ** & & * \\
\hline Subcutaneous fat (g/day) & 12.3 & 5.7 & 0.65 & $* * *$ & & & 16.7 & 26.8 & 1.92 & ** & & \\
\hline Intermuscular fat (g/day) & 3.3 & 1.8 & 0.25 & ** & & & 4.1 & 4.7 & 1.30 & & & \\
\hline \multicolumn{13}{|c|}{ Deposition rates in $m$. longissimus } \\
\hline Muscle (g/day) & 22.0 & 17.1 & 0.77 & $* * *$ & & & 22.6 & 19.3 & 2.73 & & * & * \\
\hline Protein (g/day) & 5.1 & 4.0 & 0.17 & $* * *$ & & & 5.9 & 4.9 & 0.94 & & * & * \\
\hline Lipid (g/day) & 0.41 & 0.31 & 0.05 & & & & 0.68 & 0.62 & 0.08 & & & \\
\hline Collagen (g/day) & 0.10 & 0.08 & 0.01 & & & & 0.05 & 0.04 & 0.01 & & ** & \\
\hline \multicolumn{13}{|c|}{ Deposition rates in $m$. biceps femoris ${ }^{\ddagger}$} \\
\hline Muscle (g/day) & 10.8 & 8.0 & 0.37 & $* * *$ & & & 10.7 & 9.9 & 1.08 & & & \\
\hline Protein (g/day) & 2.4 & 1.8 & 0.08 & $* * *$ & & & 2.5 & 2.3 & 0.23 & & & \\
\hline Lipid (g/day) & 0.27 & 0.13 & 0.01 & $* * *$ & & & 0.19 & 0.32 & 0.05 & * & & \\
\hline Collagen (g/day) & 0.08 & 0.06 & 0.01 & $* *$ & & & 0.04 & 0.01 & 0.01 & $* * *$ & & \\
\hline
\end{tabular}

${ }^{\top}$ Significance for the effects of feeding regimen $(F)$, sex $(S)$, and their interaction $(F \times S)$.

${ }^{\ddagger}$ Measurements on whole ham and $\mathrm{m}$. biceps femoris were carried out on only 10 animals per feeding regimen for the 80-110 kg LW period.

Muscle, protein and fat deposition in ham and muscles during growing and finishing periods

Muscle, protein and fat deposition rates in ham and in LM and $\mathrm{BF}$ muscles of $\mathrm{AL}$ and RA pigs slaughtered at 30,80 and $110 \mathrm{~kg} \mathrm{LW}$ were calculated from weight measurements and chemical analyses (Table 5). During the growing (restriction) period, at the ham level, RA pigs exhibited lower deposition rates of fat $(-52 \%, P<0.001)$ and muscle $(-20 \%, P<0.001)$ compared with controls. Over the same period, in both LM and BF muscles, RA pigs showed decreased deposition rates of whole muscle, i.m. protein $\left(-23 \%\right.$ on average), lipid (up to $-50 \%$ in the $\mathrm{BF}_{\text {, }}$ $P<0.001)$ and collagen $(-23 \%)$, even though the difference between the groups for LM lipid deposition did not 
reach significance $(P=0.087)$. Calculated deposition rates for muscle, fat and protein in ham and in muscles did not differ between sexes.

During the finishing (re-alimentation) period, a 52\% higher ham fat deposition rate was observed in RA pigs compared with AL pigs. This effect was more $(P<0.05)$ pronounced for females $(+160 \%$ total fat ham deposition, $P<0.05)$ than for castrated males $(+16 \%, P>0.05)$. Muscle deposition in ham remained lower $(-21 \%$, $P<0.05)$ in RA pigs than in AL pigs during finishing. In muscles, higher lipid $(+68 \%)$ and lower collagen deposition rates were found in the BF of RA pigs compared with $\mathrm{AL}$ pigs, whereas whole muscle and protein deposition rates in $\mathrm{BF}$, and whole muscle, protein, lipid and collagen deposition rates in LM did not significantly differ between feeding strategies. Sex had no significant effect on muscle, fat, protein and collagen deposition at both ham and BF muscle levels during the finishing period. By contrast, females had higher $(P<0.05)$ levels of muscle, protein and collagen deposition rates than castrated males in the LM. Significant interactions between sex and feeding strategy were found for LM muscle and protein deposition rates, with higher $(P<0.05)$ levels in AL females than in RA females, or AL and RA castrated males.

\section{Discussion}

In this study, a restriction-re-alimentation feeding was investigated as a possible strategy to increase muscle lipid deposition and therefore to improve pork eating quality (Bejerholm and Barton-Gade, 1986; Fernandez et al., 1999). Within muscle, number and size of adipocytes interspersed between myofibre fasciculi are the main determinants of lipid content variability (Hood and Allen, 1973; Gondret and Lebret, 2002). In a previous study, we showed that the number of i.m. adipocytes increases with age independent of the feeding strategy, while their diameter is enlarged with energy intake (Gondret and Lebret, 2002). We thus speculated that the RA feeding strategy could increase lipid storage capacity (through a higher number of i.m. adipocytes in older RA pigs than AL pigs) and lipid accretion in enlarged adipocytes (through a high final energy intake for RA pigs). The second purpose of this study was to characterise better the consequences of compensatory feed intake on fat and protein deposition rates in carcass, valuable lean cuts and skeletal muscles of pigs slaughtered at $110 \mathrm{~kg}$ market weight.

\section{Dynamic variations in growth rate and hormone levels according to feeding strategy}

As expected, the $30 \%$ reduction in feed intake decreased the growth rate by around 30\% in accordance with other studies on restricted pigs raised individually (Campbell et al., 1983; Lebret et al., 2001) or in groups (Donker et al., 1986). Thereafter, the RA feeding strategy led to a compensatory feed intake during finishing, resulting in a slight increase in average daily gain (compensatory growth) compared with controls. RA pigs were thus 23 days older than the AL pigs, as expected from our experimental design. Changes in plasma IGF-1 with feeding level were also observed. Ad libitum feeding of RA pigs for 10 days allowed plasma IGF-1 concentration to reach levels found in AL pigs, in agreement with Therkildsen et al. (2004). In cattle, an increase in IGF-1 levels during re-feeding to values higher than those found in control animals was reported by Hornick et al. (2000). Although a transient increase in plasma IGF-1 cannot be excluded in the present study, the observed response is consistent with the slight increase in the final growth rate of RA pigs.

The 7\% higher daily gain of RA pigs with re-feeding is in the low range of values reported in the literature, with $6-18 \%$ higher growth rate in re-fed compared with control pigs (Campbell et al., 1983; Donker et al., 1986; Oksbjerg et al., 2002). This might have resulted from the impaired feed efficiency in the RA pigs during re-alimentation even though inconsistent data have been reported in the literature. Although Donker et al. (1986) did not observe any significant effect of re-feeding on this trait, an improved feed efficiency was reported in pigs kept individually and exhibiting a marked compensatory growth response (Campbell et al., 1983; Oksbjerg et al., 2002; Therkildsen et al., 2004). The discrepancies between studies in the level of compensatory growth response may be explained by differences in the onset and duration of the restriction and refeeding periods, or in the physiological stage at start of restriction, or re-feeding (Campbell et al., 1983; Mason et al., 2005). Moreover, changes from restricted to ad libitum feeding as well as final slaughter generally occurred at a given age (and therefore at lighter LW) in most of these studies, instead of at a given LW.

Responses of restrictive and compensatory feeding at the carcass level

Feed restriction increased carcass lean meat content and proportion of lean cuts and decreased the proportion of fat tissues, in agreement with Campbell et al. (1983), Donker et al. (1986) and Lebret et al. (2001). Ham composition, which closely reflects carcass composition (Desmoulin et al., 1988), was also modified towards higher muscle and lower fat content. One important finding is that most of the differences reported between RA and AL pigs for carcass composition at LW80 were no longer significant at LW110. Indeed, calculations of lean and fat tissue deposition in the ham demonstrated a high increase in fat tissue accretion during re-alimentation, particularly at the subcutaneous level, whereas lean tissue accretion remained lower in RA pigs than in control pigs. In addition, the differences in gut, liver and perirenal fat weights noticed between RA and $A L$ pigs at LW80 were no longer significant at LW110, indicating a higher growth rate of these organs in RA pigs than in AL pigs with re-feeding. The modified composition of weight gain through higher fat than lean deposition 
together with the higher growth rate of organs during refeeding confirms previous findings (Bikker et al., 1996b; Blanchard et al., 1999; Skiba et al., 2004) and indicates that compensation mainly occurs in the tissues and organs discriminated by feed restriction. Consequently, carcass composition did not differ between feeding regimen at $110 \mathrm{~kg}$ LW, except a lower backfat depth that led to a higher $\mathrm{LMC}_{\mathrm{FoM}}$ in the RA pigs. Similar findings have been reported in pigs re-fed over a short period (9 and 27 days of realimentation) and raised by groups of two or individually compared with ad libitum fed pigs (Blanchard et al., 1999; Therkildsen et al., 2002), whereas extended re-alimentation period (50 to 59 days) for individually raised pigs did not influence carcass leanness (Therkildsen et al., 2004). Altogether, this indicates that duration of re-alimentation period and age or weight at final slaughter affects carcass composition.

Interestingly, physiological response to dietary restriction and subsequent re-feeding differed between sexes. Indeed, we found a complete recovery of carcass fatness in re-fed females, but not in castrated males, even though the intensity of compensatory feed intake was similar for RA castrated males and females $(P=0.71)$. Most of the studies describing the compensatory growth response in pigs usually involved only one gender. However, Therkildsen et al. (2002) did not find any significant interaction between feeding regimen and sex on growth and carcass composition traits when using castrated males and females. The possible gender effect on composition of compensatory growth requires further investigations.

\section{Composition of muscle weight gain and consequences on meat quality}

This study clearly indicates that the effect of feeding strategy differs between muscles of economic interest. The decrease in BF lipid concentration with feed restriction confirms previous results (Lebret et al., 2001) and further demonstrates a stronger effect of restriction on lipid than on protein or collagen deposition rates. Surprisingly, we did not observe any difference in LM lipid concentration between RA and AL pigs after feed restriction, whereas a decrease in lipid concentration is generally reported in this muscle (Wood et al., 1996; Lebret et al., 2001). Re-alimentation of RA pigs did not affect lipid deposition in LM but highly increased lipid accretion in BF compared with $\mathrm{AL}$ pigs. However, this higher lipid deposition rate was not sufficient to increase lipid concentration above the concentration of $A L$ pigs. The duration of the re-alimentation period of RA pigs (28 days) was probably too short to induce such an effect.

Further investigations, in particular, concerning muscle energetic (lipogenic) metabolism are needed to understand the muscle-associated differences observed in response to feeding strategy. It is generally considered that a restriction-re-alimentation feeding strategy has no significant effect on LM lipid concentration in pigs slaughtered at the same age (Kristensen et al., 2002; Therkildsen et al., 2002; Mason et al., 2005). Blanchard et al. (1999) did not either find any effect on LM lipid at $90 \mathrm{~kg} \mathrm{LW}$ after re-feeding from $60 \mathrm{~kg}$ onwards, but a lower LM lipid level in pigs re-fed from 75 to $90 \mathrm{~kg} \mathrm{LW}$.

Apart from lipids, concentration and heat-solubility of collagen are thought to influence meat quality traits (Bailey and Light, 1989). We reported a lower collagen deposition in $\mathrm{BF}$ of $\mathrm{RA}$ pigs compared with $\mathrm{AL}$ pigs during realimentation, giving rise to lower muscle collagen concentration in the RA pigs at $110 \mathrm{~kg} \mathrm{LW}$. The feeding strategy did not influence $B F$ weight at $110 \mathrm{~kg}(1.27$ and $1.25 \mathrm{~kg}$ for $\mathrm{AL}$ and RA pigs, respectively, $P=0.66)$. Therefore, the lower collagen concentration of RA pigs did not result from a higher 'dilution effect' of collagen as a consequence of a higher muscle fibre hypertrophy. Rather, it may be explained by a lower synthesis and/or a higher catabolism level of muscle collagen in the RA pigs. It was demonstrated in bovine muscles that a high growth rate subsequent to under-nutrition might increase the thermal solubility of collagen due to less cross-linking in newly synthesised collagen (Bailey and Light, 1989). By contrast, we reported a trend for a lower collagen thermal solubility in the LM of RA pigs compared with AL pigs $(P=0.08)$. Because mechanical and thermal stability of collagen increase with age during normal growth (Lebret et al., 1998; Purslow, 2005), the lower heat-solubility of collagen in LM in RA pigs is probably explained by their higher age at $110 \mathrm{LW}$.

In conclusion, compared with ad libitum feeding, the RA feeding strategy increased the age of pigs at market weight, as expected. During re-alimentation after feed restriction, RA pigs showed compensatory feed intake and a slight, although non-significant, increase in growth rate (=compensatory growth). Composition of weight gain was modified during both restriction and re-alimentation periods. Restriction affected fat above lean tissue deposition. At the body level, re-alimentation advantaged fat and internal organ growth over lean deposition, particularly in females. Composition of weight gain during re-alimentation differed according to muscle, with an increased lipid deposition in $B F$, but not in LM. However, this remained insufficient to enhance BF lipid concentration in RA pigs compared with $\mathrm{AL}$ pigs at market slaughter weight. Consequences of RA feeding strategy on pork eating quality remain to be evaluated. But it can be suggested that modifications of onset, duration and/or severity of restriction and duration of re-alimentation periods should be tested to optimise the effects of this feeding strategy on i.m. lipid deposition and therefore obtain a positive influence on pork eating quality.

\section{Acknowledgements}

The excellent assistance of the staff of the experimental farm, slaughterhouse and laboratories from INRA-SENAH, in particular N. Bonhomme, is gratefully acknowledged. 


\section{References}

Association of Official Analytical Chemists 1990. Official methods of analysis, 15th edition. AOAC, Arlington, VA, USA.

Bailey AJ and Light ND 1989. Connective tissue in meat and meat products. Elsevier Science Publishers, Barking, UK.

Bejerholm C, Barton-Gade P, 1986. Effect of intramuscular fat level on eating quality of pig meat. Proceedings of the 32nd European meeting. Meat research workers, pp. 389-391. Ghent, Belgium.

Bergman L and Loxley R 1963. Two improved and simplified methods for the spectrophotometric determination of hydroxyproline. Analytical Chemistry 35, 1961-1965.

Bikker P, Verstegen MWA, Kemp B and Bosch MW 1996a. Performance and body composition of finishing gilts ( 45 to $85 \mathrm{~kg}$ ) as affected by energy intake and nutrition in earlier life: I. Growth of the body and body components. Journal of Animal Science 74, 806-816.

Bikker P, Verstegen MWA and Campbell RG 1996b. Performance and body composition of finishing gilts ( 45 to $84 \mathrm{~kg}$ ) as affected by energy intake and nutrition in earlier life: II. Protein and lipid accretion in body components. Journal of Animal Science 74, 817-826.

Blanchard PJ, Ellis M, Warkup CC, Hardy B, Chadwick JP and Deans GA 1999. The influence of rate of lean and fat tissue development on pork eating quality. Animal Science 68, 477-485.

Campbell R, Taverner M and Curic D 1983. Effects of feeding level from 20 to $45 \mathrm{~kg}$ on the performance and carcass composition of pigs grown to $90 \mathrm{~kg}$ live weight. Livestock Production Science 10, 265-272.

Daumas G, Causeur D, Dhorne T and Schollhammer E 1998. Pig carcass grading methods authorized in France in 1997. Journées Recherche Porcine en France $30,1-6$.

Desmoulin B, Ecolan P and Bonneau M 1988. Estimation de la composition tissulaire des carcasses de porc: récapitulatif de diverses méthodes utilisables en expérimentation. INRA Productions Animales 1, 59-64.

Donker RA, Hartog LA, Brascamp EW, Merks JWM, Noordewier GJ and Buiting GAJ 1986. Restriction of feed intake to optimize the overall performance and composition of pigs. Livestock Production Science 15, 353-365.

Ellis M, Webb AJ, Avery PJ and Brown I 1996. The influence of terminal sire genotype, sex, slaughter weight, feeding regime and slaughter-house on growth performance and carcass and meat quality in pigs and on the organoleptic properties of fresh pork. Animal Science 62, 521-530.

Etherington DE and Sims TJ 1981. Detection and estimation of collagen. Journal of the Science of Food and Agriculture 32, 539-546.

Fernandez X, Monin G, Talmant A, Mourot J and Lebret B 1999. Influence of intramuscular fat content on the quality of pig meat -1 . Composition of the lipid fraction and sensory characteristics of $m$. longissimus lumborum. Meat Science 53, 59-65.

Folch J, Lees M and Stanley GHS 1957. A simple method for the isolation and purification of total lipids from animal tissues. Journal of Biological Chemistry $226,497-509$

Gondret F and Lebret B 2002. Feeding intensity and dietary protein leve affect adipocyte cellularity and lipogenic capacity of muscle homogenates in growing pigs, without modification of the expression of sterol regulatory element binding protein. Journal of Animal Science 80 3184-3193.

Hill F 1966. The solubility of intramuscular collagen in meat animals of various ages. Journal of Food Science 31, 161-166.

Hood RL and Allen CE 1973. Cellularity of bovine adipose tissue. Journal of Lipid Research 14, 605-610.
Hornick JL, Van Eenaeme C, Gerard O, Dufrasne I and Istasse L 2000. Mechanisms of reduced and compensatory growth. Domestic Animal Endocrinology 19, 121-132.

INRA-AFZ 2002. Tables de composition et de valeur nutritive des matières premières destinées aux animaux d'élevage. INRA, Paris, France.

Kristensen L, Therkildsen M, Riis B, Sorensen MT, Oksbjerg N, Purslow PP and Ertbjerg P 2002. Dietary-induced changes of muscle growth rate in pigs: effects on in vivo and post mortem muscle proteolysis and meat quality. Journal of Animal Science 80, 2862-2871.

Kristensen L, Therkildsen M, Aaslyng MD, Oksbjerg N and Ertbjerg P 2004. Compensatory growth improves meat tenderness in gilts but not in barrows. Journal of Animal Science 82, 3617-3624.

Lebret B, Listrat A and Clochefert N 1998. Age-related changes in collagen characteristics of porcine loin and ham muscles. In Proceedings of the 44th international congress of meat science and technology, vol. II, pp. 718-719. Barcelona, Spain.

Lebret B, Juin H, Noblet J and Bonneau M 2001. The effects of two methods of increasing age at slaughter on carcass and muscle traits and meat sensory quality in pigs. Animal Science 72, 87-94.

Louveau I and Bonneau M 1996. Effect of a growth hormone infusion on plasma insulin-like growth factor-I in Meishan and Large White pigs. Reproduction Nutrition Development 36, 301-310.

Mason LM, Hogan SA, Lynch A, O'Sullivan K, Lawlor PG and Kerry JP 2005. Effects of restricted feeding and antioxidant supplementation on pig performance and quality characteristics of longissimus dorsi muscle from Landrace and Duroc pigs. Meat Science 70, 307-317.

Métayer A and Daumas G 1998. Estimation of the lean meat content of pig carcasses using the measurement of different cuts. Journées Recherche Porcine en France 30, 7-11.

Oksbjerg N, Sorensen MT and Vestergaard M 2002. Compensatory growth and its effect on muscularity and technological meat quality in growing pigs. Acta Agriculturae Scandinavia, Section A - Animal Science 52, 85-90.

Prunier A, Martin C, Mounier AM and Bonneau M 1993. Metabolic and endocrine changes associated with undernutrition in the peripubertal gilt. Journal of Animal Science 71, 1887-1894.

Purslow PP 2005. Intramuscular connective tissue and its role in meat quality. Meat Science 70, 435-447.

Quiniou N, Noblet J, Van Milgen J and Dourmad JY 1995. Effect of energy intake on performance, nutrient and tissue gain and protein and energy utilization in growing boars. Animal Science 61, 133-143.

Skiba G, Fandrejewski H, Raj S, and Weremko D, 2004. Compensatory response of pigs kept in different feeding strategies. Proceedings of the sustainable pork production: welfare, nutrition and consumer attitudes, pp. 68-79. Copenhagen, Denmark.

Statistical Analysis Systems Institute 2000. SAS for SunOS, version 8.01.01. SAS Institute, Inc., Cary, NC, USA.

Therkildsen M, Riis B, Karlsson A, Kristensen L, Ertbjerg P, Purslow PP, Dall Aaslyng MD and Oksbjerg N 2002. Compensatory growth response in pigs, muscle protein turn-over and meat texture: effects of restriction/realimentation period. Animal Science 75, 367-377.

Therkildsen $M$, Vestergaard $M$, Busk $H$, Jensen $M$, Riis $B$, Karlsson $A$ Kristensen L, Ertbjerg P and Oksbjerg N 2004. Compensatory growth in slaughter pigs - in vitro muscle protein turnover at slaughter, circulating IGF-I, performance and carcass quality. Livestock Production Science 88, 63-75.

Wood JD, Brown SN, Nute GR, Whittington FM, Perry AM, Johnson SP and Enser M 1996. Effects of breed, feed level and conditioning time on the tenderness of pork. Meat Science 44, 105-112. 